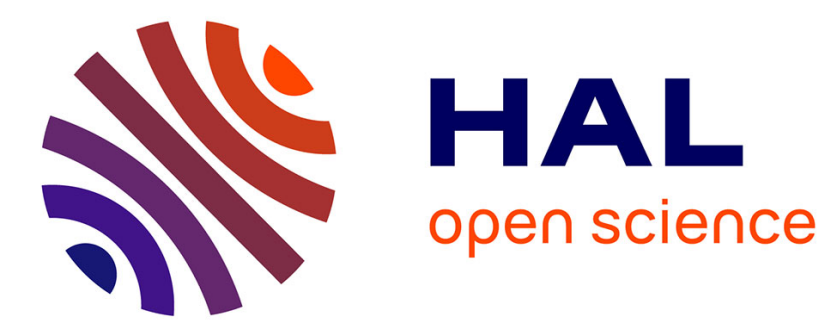

\title{
A neuroscientific approach to increase gender equality
}

Christiane Schreiweis, Emmanuelle Volle, Alexandra Durr, Alexandra Auffret, Cécile Delarasse, Nathalie George, Magali Dumont, Bassem Hassan, Nicolas M Renier, Charlotte Rosso, et al.

\section{- To cite this version:}

Christiane Schreiweis, Emmanuelle Volle, Alexandra Durr, Alexandra Auffret, Cécile Delarasse, et al. A neuroscientific approach to increase gender equality. Nature Human Behaviour, 2019, 3 (12), pp.1238-1239. 10.1038/s41562-019-0755-7 . hal-03006221

\section{HAL Id: hal-03006221 \\ https://hal.science/hal-03006221}

Submitted on 15 Dec 2020

HAL is a multi-disciplinary open access archive for the deposit and dissemination of scientific research documents, whether they are published or not. The documents may come from teaching and research institutions in France or abroad, or from public or private research centers.
L'archive ouverte pluridisciplinaire $\mathbf{H A L}$, est destinée au dépôt et à la diffusion de documents scientifiques de niveau recherche, publiés ou non, émanant des établissements d'enseignement et de recherche français ou étrangers, des laboratoires publics ou privés. 


\section{Correspondence}

\section{A neuroscientific approach to increase gender equality}

To the Editor - Gender inequality is prevalent in many countries and cultures, and it persists despite our awareness of it and the policies some countries have put in place to combat it. France, for example, offers significant opportunities to enable women to handle both career and personal life: it provides a social healthcare system that was ranked No. 1 by the World Health Organization in 2000, a legal framework promoting gender equality ${ }^{1}$, and relatively accessible and affordable childcare and scholastic infrastructure. Herein lies the paradox: despite France having a strong reputation for providing a favourable social and professional context, French women still lag behind French men in their careers.

One of the main reasons gender inequality persists despite this supportive infrastructure is the perpetuation of implicit biases and gender stereotypes. These shape the way we behave, our ability to recognize unequal treatment, the willingness of disadvantaged individuals to speak up, and even the research conducted in institutions that have been raising awareness of gender inequalities in science since $2001^{2,3}$ (http://www.cnrs.fr/mpdf/; https://www.inserm.fr/gouvernance-organisation/cs). Current research indicates that we grow into our anticipated roles (for example, men are bread winners, women are caretakers) rather than being predisposed for them ${ }^{2-6}$. As the philosopher Simone de Beauvoir wrote: "women are not born but rather made". Thus, a major challenge, as recognized in cognitive and social neurosciences, is to defeat implicit gender biases.
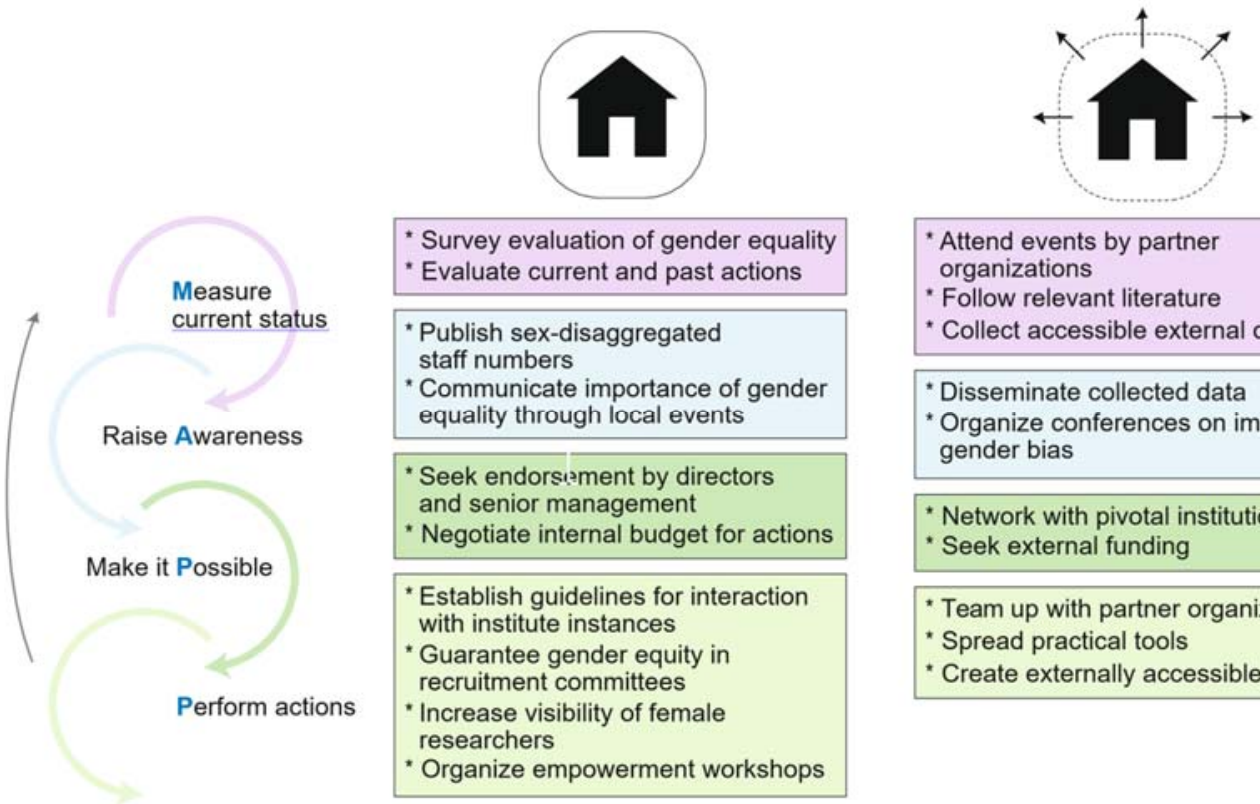

* Attend events by partner organizations

- Follow relevant literature

* Collect accessible external data

" Disseminate collected data

* Organize conferences on implicit gender bias

- Network with pivotal institutions

Seek external funding

* Team up with partner organizations

* Spread practical tools

Create externally accessible media

Fig. 1 | Roadmap for gender equality. Iterative phases 'measure current status', 'raise awareness', 'make it possible', and 'perform actions' (MAPP) are intended to accelerate politics towards gender equality. A non exhaustive list of concrete actions depicted here include establishing equal visibility of female researchers, organizing empowerment workshops, promoting equality of female leadership and regulating interaction with any institutional instance. External actions, based on networking and on interacting with and sharing information, tools and actions between research institutes and pivotal organizations, are also essential. The potential effect of performed actions is then assessed and adapted in a next MAPP cycle.

To pinpoint existing implicit gender bias and fight gender inequality, a group of neuroscientists at the Institut du Cerveau et de la Moelle Épinière leveraged their knowledge of cognitive neuroscience to develop a roadmap of practical steps to fight gender inequality. These iterating steps include collecting and communicating data, seeking endorsement from directors and management, and implementing actions (Fig. 1). Internal sex-disaggregated data acquired before the onset of our initiative in April 2017 showed that only $26 \%$ of women occupied (co-) group leadership in our institute, which is composed of $63 \%$ women. Other sex- disaggregated data showed that $25 \%$ of the speakers invited to present at the weekly scientific seminar were female, effectively diminishing the visibility of neuroscientific research performed by women. These data inspired us to establish a gender equity committee to actively combat gender biases. By raising awareness of the gender inequality in key positions within our institutions, we have raised the pool of female invited 
speakers from $25 \%$ to $44 \%$ and female team leadership proportion to $31 \%$ in the last 1.5 years (as of December 2018). We also enforce gender-neutral phrasing in official documents, discuss the strategy of future recruitments and host biannual empowerment training, as well as educational workshops on implicit gender biases. Taken together, these activities share a common goal: moving towards gender parity by exposing the implicit biases enacted by both sexes and actively combatting them by, for example, promoting and inviting more women. Our success over the last 1.5 years highlights the importance of complementing existing, larger country-level policies with explicit measures facilitating the recognition of implicit biases we perpetuate. Only by combining these two will we reach gender equality.

Christiane Schreiweis*, Emmanuelle Volle, Alexandra Durr, Alexandra Auffret, Cécile Delarasse, Nathalie George, Magali Dumont, Bassem A. Hassan, Nicolas Renier, Charlotte Rosso, Michel Thiebaut de Schotten,

Eric Burguière and Violetta Zujovic

Institut du Cerveau et de la Moelle Épinière (ICM), Inserm U 1127, CNRS UMR 7225,

Sorbonne Université, Paris, France.

*e-mail: c.schreiweis@icm-institute.org

\section{References}

1. Delzangles, B. Rev. Droits L'homme https://doi.org/10.4000/revdh.3258 (2017).

2. Ellemers, N. Annu. Rev. Psychol. 69, 275-298 (2018).

3. Rippon, G. The Gendered Brain: The New Neuroscience that Shatters the Myth of the Female Brain (Bodley Head, 2019).

4. Amodio, D. M. Nat. Rev. Neurosci. 15, 670-682 (2014).

5. Bian, L., Leslie, S. J. \& Cimpian, A. Science 355, 389-391 (2017).

6. Eagly, A. H. \& Wood, W. Perspect. Psychol. Sci. 8, 340-357 (2013).

7. de Beauvoir, S. Le Deuxième Sexe (Gallimard, 1949).

Acknowledgements

C.S. thanks the L'Oréal-UNESCO Foundation "For Women in Science" for the award of a postdoctoral fellowship in 2016.

\section{Author contributions}

C.S., E.V., A.D., and V.Z. wrote the paper; C.S., E.V., A.D., A.A., C.D., N.G., M.D., B.A.H., N.R., C.R., M.T.d.S., E.B., and V.Z. edited the paper and are the founding members of the XX Initiative.

Competing interests

The authors declare no competing interests. 